\title{
Lack of association between screening interval and cancer stage in Lynch syndrome may be accounted for by over- diagnosis; a prospective Lynch syndrome database report
}

Toni T. Seppälä ${ }^{1,2^{*}}$ (D, Aysel Ahadova ${ }^{3}$, Mev Dominguez-Valentin ${ }^{4,5}$, Finlay Macrae ${ }^{6,7}$, D. Gareth Evans ${ }^{8}$, Christina Therkildsen ${ }^{9}$, Julian Sampson ${ }^{10}$, Rodney Scott ${ }^{11}$, John Burn ${ }^{12}$, Gabriela Möslein ${ }^{13}$, Inge Bernstein ${ }^{14}$, Elke Holinski-Feder ${ }^{15,16}$, Kirsi Pylvänäinen ${ }^{17}$, Laura Renkonen-Sinisalo ${ }^{1}$, Anna Lepistö ${ }^{1}$, Charlotte Kvist Lautrup ${ }^{18}$, Annika Lindblom ${ }^{19}$, John-Paul Plazzer ${ }^{6}$, Ingrid Winship ${ }^{6,7}$, Douglas Tjandra ${ }^{6}$, Lior H. Katz ${ }^{20}$, Stefan Aretz ${ }^{21}$, Robert Hüneburg ${ }^{22,23}$, Stefanie Holzapfel ${ }^{22,23}$, Karl Heinimannn ${ }^{24}$, Adriana Della Valle ${ }^{25}$, Florencia Neffa ${ }^{25}$, Nathan Gluck ${ }^{26}$, Wouter H. de Vos tot Nederveen Cappel ${ }^{27}$, Hans Vasen ${ }^{28}$, Monika Morak ${ }^{15,16}$, Verena Steinke-Lange ${ }^{15,16}$, Christoph Engel ${ }^{29}$, Nils Rahner ${ }^{30}$, Wolff Schmiegel ${ }^{31}$, Deepak Vangala ${ }^{31}$, Huw Thomas ${ }^{32}$, Kate Green ${ }^{8}$, Fiona Lalloo ${ }^{8}$, Emma J. Crosbie ${ }^{33}$, James Hill ${ }^{8}$, Gabriel Capella ${ }^{34,35}$, Marta Pineda ${ }^{34,35}$, Matilde Navarro ${ }^{34,35}$, Ignacio Blanco ${ }^{34,35}$, Sanne ten Broeke ${ }^{36}$, Maartje Nielsen ${ }^{37}$, Ken Ljungmann ${ }^{38}$, Sigve Nakken ${ }^{4}$, Noralane Lindor ${ }^{39}$, lan Frayling ${ }^{10}$, Eivind Hovig ${ }^{4,40}$, Lone Sunde ${ }^{41}$, Matthias Kloor ${ }^{3}$, Jukka-Pekka Mecklin ${ }^{42,43}$, Mette Kalager ${ }^{4,44,45}$ and Pål Møller ${ }^{4,13,5}$

\footnotetext{
Abstract

Background: Recent epidemiological evidence shows that colorectal cancer (CRC) continues to occur in carriers of pathogenic mismatch repair (path_MMR) variants despite frequent colonoscopy surveillance in expert centres. This observation conflicts with the paradigm that removal of all visible polyps should prevent the vast majority of CRC in path_MMR carriers, provided the screening interval is sufficiently short and colonoscopic practice is optimal.

Methods: To inform the debate, we examined, in the Prospective Lynch Syndrome Database (PLSD), whether the time since last colonoscopy was associated with the pathological stage at which CRC was diagnosed during prospective surveillance. Path_MMR carriers were recruited for prospective surveillance by colonoscopy. Only variants scored by the InSiGHT Variant Interpretation Committee as class 4 and 5 (clinically actionable) were included. CRCs detected at the first planned colonoscopy, or within one year of this, were excluded as prevalent cancers.

(Continued on next page)
}

\footnotetext{
* Correspondence: toni.t.seppala@hus.fi; toni.seppala@fimnet.fi

${ }^{1}$ Department of Surgery, Helsinki University Central Hospital, P.O. Box 340, 00029 HUS Helsinki, Finland

${ }^{2}$ University of Helsinki, Helsinki, Finland

Full list of author information is available at the end of the article
}

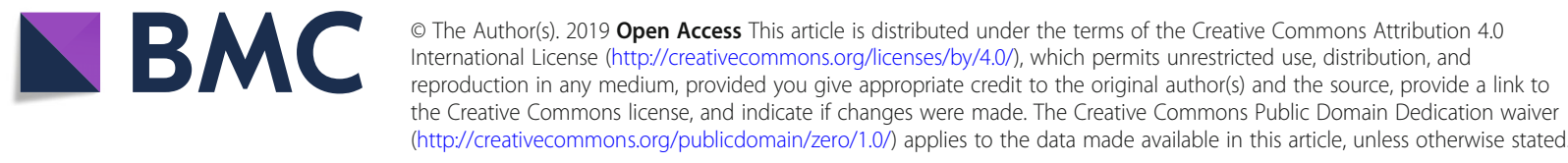


(Continued from previous page)

Results: Stage at diagnosis and interval between last prospective surveillance colonoscopy and diagnosis were available for 209 patients with 218 CRCs, including 162 path_MLH1, 45 path_MSH2, 10 path_MSH6 and 1 path_PMS2 carriers. The numbers of cancers detected within <1.5, 1.5-2.5, 2.5-3.5 and at $>3.5$ years since last colonoscopy were 36, 93, 56 and 33, respectively. Among these, 16.7, 19.4, 9.9 and 15.1\% were stage III-IV, respectively $(p=0.34)$. The cancers detected more than 2.5 years after the last colonoscopy were not more advanced than those diagnosed earlier $(p=0.14)$.

Conclusions: The CRC stage and interval since last colonoscopy were not correlated, which is in conflict with the accelerated adenoma-carcinoma paradigm. We have previously reported that more frequent colonoscopy is not associated with lower incidence of CRC in path_MMR carriers as was expected. In contrast, point estimates showed a higher incidence with shorter intervals between examinations, a situation that may parallel to over-diagnosis in breast cancer screening. Our findings raise the possibility that some CRCs in path_MMR carriers may spontaneously disappear: the host immune response may not only remove CRC precursor lesions in path_MMR carriers, but may remove infiltrating cancers as well. If confirmed, our suggested interpretation will have a bearing on surveillance policy for path_MMR carriers.

Keywords: Mismatch repair, Microsatellite instability, Lynch syndrome, Hereditary cancer, Colorectal cancer, Hereditary nonpolyposis colorectal cancer, Colonoscopy, Endoscopy, Surveillance, Screening, Over-diagnosis

\section{Background}

It is commonly agreed that adenomas in the colon may develop to infiltrating cancers, but the probability for one single adenoma to do so within a few years is low [1]. Most hereditary colorectal cancers (CRCs) are not associated large numbers of adenomas in the intestine, and to indicate that this is different from the situation in familial adenomatous polyposis, the term "hereditary non-polyposis colorectal cancer" (HNPCC) was agreed [2]. HNPCC patients often had a few adenomas in the large bowel at the time of CRC diagnosis, and Jass and Stewart proposed that "adenomas do not occur in large numbers in HNPCC, but develop at a young age, attain a larger size, often show a villous configuration, and are more prone to malignant conversion than sporadic adenomas". This was referred to as the "accelerated adenoma-carcinoma sequence" and became accepted as the cause of CRC in HNPCC [3]. Consequently, it was assumed that colonoscopy with removal of macroscopically visible adenomas would prevent CRC in individuals at risk for HNPCC. It was soon documented that colonoscopy with a three-year interval reduced both CRC incidence and mortality in HNPCC kindreds [4, 5]. Compared with non-HNPCC moderate-risk familial CRC, even single colonoscopy at middle-age substantially reduced risk for subsequent CRC $[6,7]$ and there was no benefit from 3-yearly colonoscopies over 6-yearly colonoscopies [8].

However, CRC continued to occur despite intensive surveillance [9]. In an attempt to reduce incident CRCs, Vasen and others proposed shortening the interval between colonoscopies from 2 to 3 years to $1-2$ years [10], now adopted as an international clinical guideline [11]. It was also agreed that extended surgery could be considered in individuals with $\mathrm{HNPCC}$ and $\mathrm{CRC}$, recognizing that secondary prevention of CRC by colonoscopy surveillance was not always reliable [11].

The mismatch repair (MMR) mechanism is ubiquitous in nature as a means of repairing DNA damage $[12,13]$, and pathogenic variants in four genes: $M L H 1, M S H 2$, MSH6 and PMS2 were identified in HNPCC [14-17]. When cells with inherited pathogenic variants acquire a second somatic mutation that inactivates the wild-type allele, the consequence may be an MMR protein deficient tumor with microsatellite instability (MSI). In view of the wide extracolonic cancer phenotype, HNPCC was re-named Lynch syndrome (LS) and restricted to inherited cancer caused by a path_MMR gene variant [18].

It has long been suspected that some cancers do not develop through adenomas in LS, but rather through a pathway without a visible precursor polyp. The paradigm that all CRC in LS could be prevented by removal of macroscopically visible precursor lesions was not confirmed, even with more frequent surveillance colonoscopy [9, 10]. The Prospective Lynch Syndrome Database (PLSD) was established to prospectively follow path_MMR carriers. A key question was to validate the paradigm that removal of macroscopically visible adenomas during repetitive colonoscopies would prevent CRC. We have previously reported that the observed lifetime cumulative incidence of CRC in path_MLH1 and path_MSH2 carriers was $43-45 \%$ despite follow-up according to national and international guidelines [19-22].

To further inform the epidemiology of CRC in path_MMR carriers subjected to repeated colonoscopies, we examined the association between the time since last colonoscopy and pathological stage of prospectively detected CRC. 


\section{Material and methods}

The PLSD database design and its inclusion criteria have been described in detail previously $[19,21]$. PLSD is an international, multicentre database recording prospective observational data on path_MMR carriers under surveillance by colonoscopy. All path_MMR carriers in each participating centre were included in the study. The demonstrated genetic variants were assumed inherited and were found by genetic testing either prior to, at, or after inclusion for follow-up. Only variants scored by the InSiGHT Governance Committee as class 4 and 5 (clinically actionable) were included. All cancers detected prior to, at or within one year after the age at the first planned and performed colonoscopy, were scored as prior or prevalent cancers and excluded from the analysis when scoring prospectively observed cancers. The surveillance strategies recommended by each participating centre are presented in Table 1.

The following information was used in the statistical analyses: sex, path_MMR variant, age at inclusion, age at last update, age at CRC, type of cancer as indicated by the first three positions in the International Classification of Diseases version 9 (ICD-9) diagnostic system, the American Joint Committee on Cancer (AJCC) stage of CRC (I-IV) and the time since the last colonoscopy preceding the diagnosis of CRC. All cancers, including cancers prior to or at inclusion, were recorded for each carrier. Inclusion was from the first prospectively planned and completed colonoscopy, and all recruits had subsequent follow-up of one year or more.

Patients with a CRC detected during prospective follow-up were studied in detail. The time since the colonoscopy before the one in which the cancer diagnosis was established, was recorded in months and categorized as $<1.5,1.5$ to $2.5,2.5$ to 3.5 or $>3.5$ years since last colonoscopy. We considered stage III-IV as advanced. We compared stage in the different time intervals since last colonoscopy, corresponding with the different clinical guidelines advocating 1, 2 or 3 year intervals between colonoscopies, as slightly longer intervals may occur for several reasons in a clinical setting. We also compared stage in dichotomized time intervals, more and less than 2.5 years, to compare the most common current recommendation of 2 years to longer intervals. We performed a sensitivity analysis excluding Finland since patients there were recommended 23 -yearly colonoscopies rather than 1-2-yearly as in the other countries and because one out of two variants in the Finnish series was not shared by others. Statistical testing was performed by SPSS version 23 (IBM, Armonk, NY, US). Chi-square test was used to test the statistical significance at the level of $\alpha=0.05$ between the different colonoscopy intervals.
All collaborating centres undertook genetic testing according to national policies. No individually identifiable data was exported to the PLSD.

\section{Results}

In the most recently updated series of the PLSD, 6350 pathogenic variant carriers of mismatch repair genes (path_MMR) were prospectively observed for 51,646 follow-up years. A total of 707 CRCs were detected, and stage and interval between last prospective surveillance colonoscopy and diagnosis were available for 209 patients with 218 (30.8\%) CRCs (9 patients had a metachronous cancer during follow-up). There were 162 path_MLH1, 45 MSH2, 10 path_MSH6 and 1 path_PMS 2 carriers.

The numbers of cancers detected within $<1.5,1.5$ to $2.5,2.5$ to 3.5 and $>3.5$ years since last colonoscopy were 36, 93, 56 and 33. Of these CRCs, 16.7, 19.4, 9.9 and $15.1 \%$ were advanced stage (III-IV), respectively ( $p=0.40$; Fig. 1a). The distribution of cancer stage were similar in the different colonoscopy intervals, $p=0.34$ (Table 2 ). The cancers detected more than 2.5 years after the last colonoscopy were not more advanced than those diagnosed earlier than 2.5 years ( $p=0.14$; Fig. 1b).

When excluding patients from Finland, we found a similar pattern as when analyzing the whole cohort. A total of 105 patients were included and 110 cancers were detected at follow-up. The numbers of cancers detected within $<1.5,1.5$ to $2.5,2.5$ to 3.5 and $\geq 3.5$ years since last colonoscopy were 22 (20\%), 53 (48.2\%), 15 (13.6\%) and 20 (18.2\%). Of these CRCs, 18.2, 26.4, 6.7 and 15.0\% were advanced stage (III-IV), respectively ( $p=0.34)$.

Mean age at cancer diagnosis was 55 years. There was no difference between the colonoscopy interval distribution of those under $(n=110)$ and those over $(n=108)$ 55 years $(p=0.138)$. Stage III cancers were slightly more frequent among those under 55 years than those over 55 years (22 versus 8 , respectively; $p=0.045$ ).

\section{Discussion}

We found that CRC stage distribution was not dependent on time since last colonoscopy. Stage distribution was similar irrespective of time since the previous colonoscopy, indicating that additional carcinogenetic mechanisms besides the accelerated adenoma-carcinoma pathway may have been instrumental in the development of some CRCs. Our findings are supported by another prospective study based on 16,327 colonoscopies in 2747 patients with path_MMR carriers [23], which found no correlation between advanced stage CRC and time since last colonoscopy.

There is convincing evidence that regular colonoscopy surveillance reduces CRC incidence and mortality in path_MMR carriers compared to no surveillance $[4,5]$, although the surveillance does not prevent the cancers 


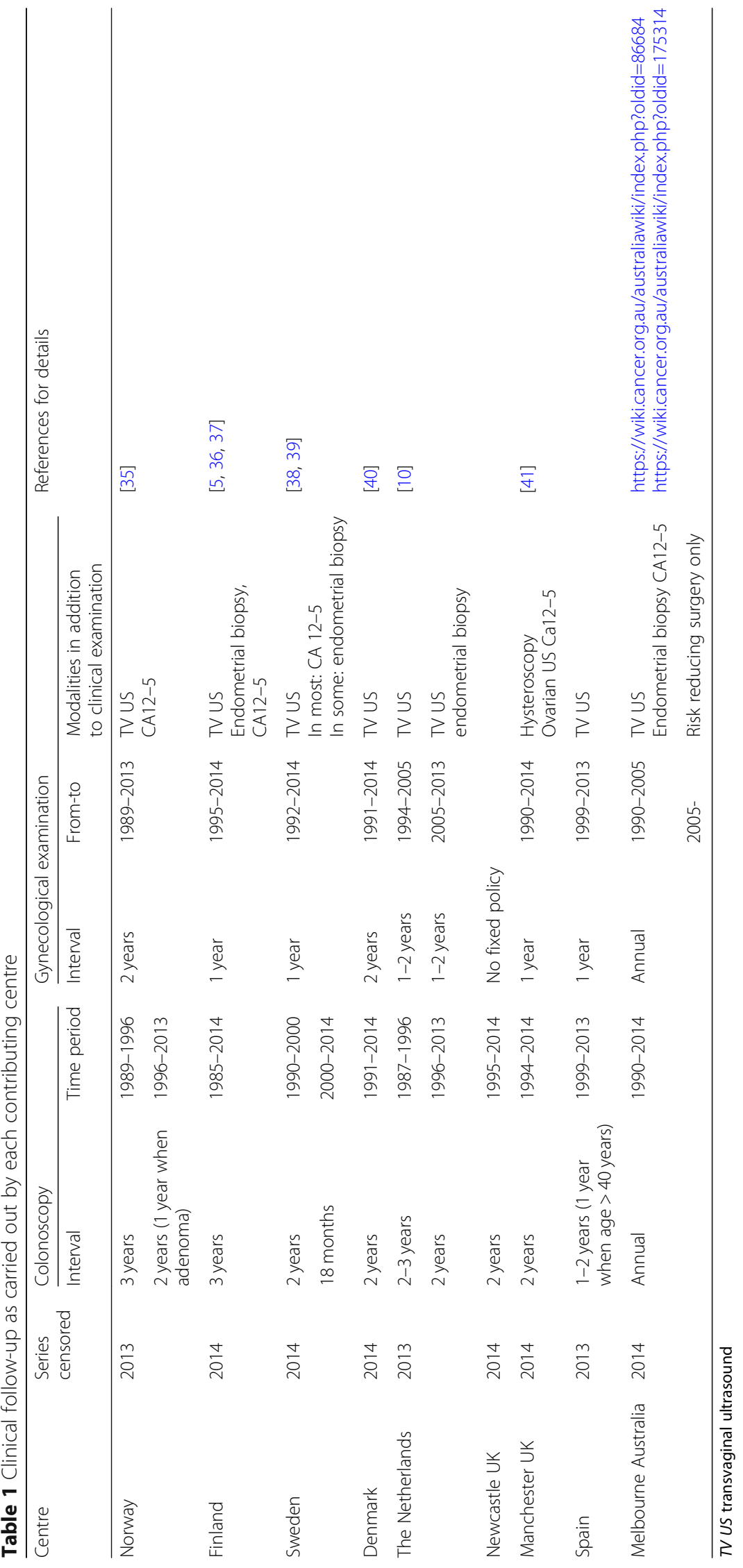




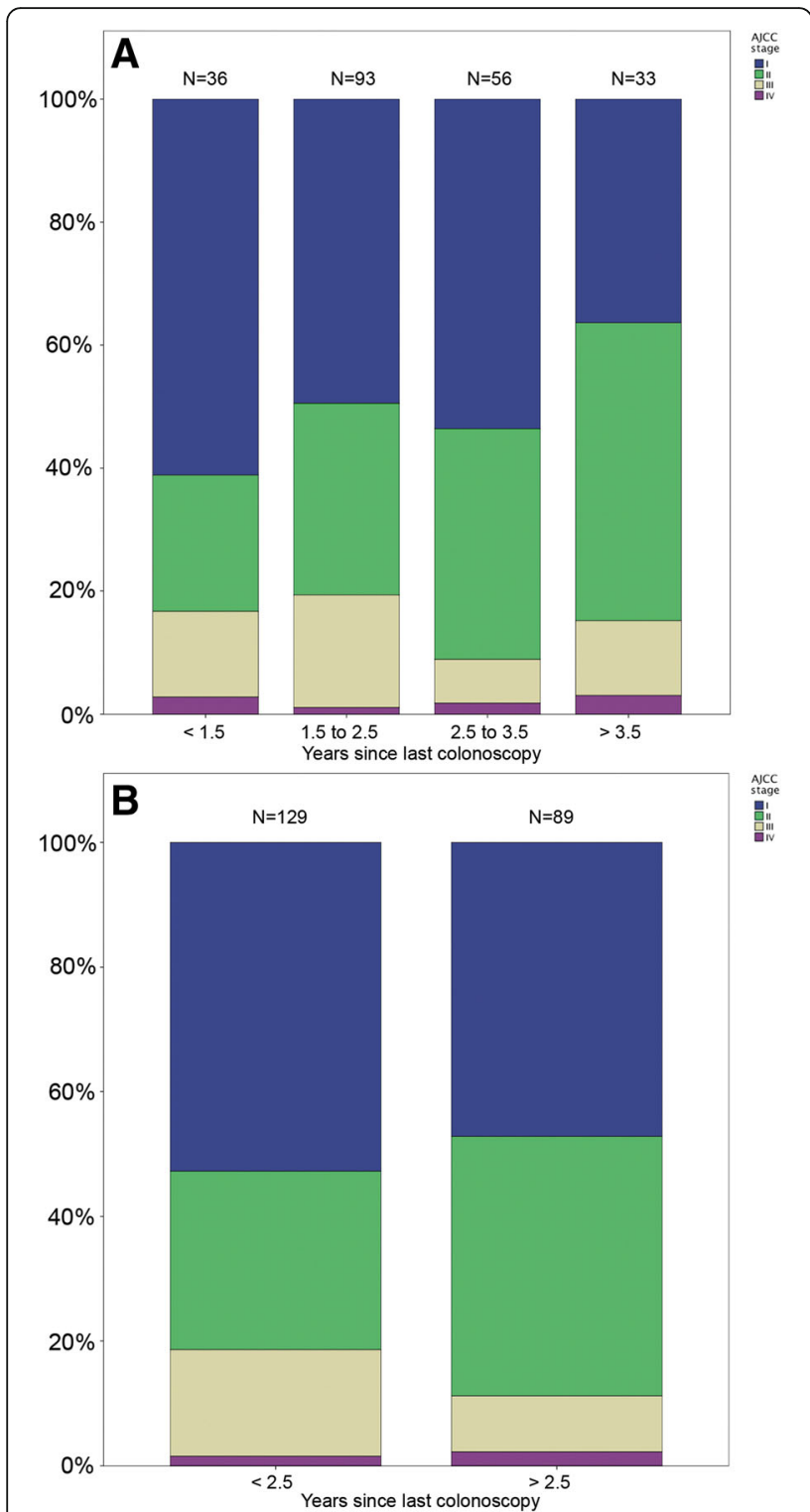

Fig. 1 Number of CRC in different AJCC stages diagnosed in the time interval since the last surveillance colonoscopy. a time since last colonoscopy in intervals of $<1.5,1.5$ to $2.5,2.5$ to 3.5 and $>3.5$ years. $\mathbf{b}$ Time intervals of less and more than 2.5 years

Table 2 Stage distribution by the time since last colonoscopy before cancer diagnosis

\begin{tabular}{lllll}
\hline & $\begin{array}{l}\text { Less than } 1.5 \\
\text { years (\%) }\end{array}$ & $\begin{array}{l}1.5 \text { to } 2.5 \\
\text { years }(\%)\end{array}$ & $\begin{array}{l}2.5 \text { to } 3.5 \\
\text { years }(\%)\end{array}$ & $\begin{array}{l}\text { Over 3.5 } \\
\text { years (\%) }\end{array}$ \\
\hline Stage I & $22(61.1)$ & $46(49.5)$ & $30(53.6)$ & $12(36.4)$ \\
Stage II & $8(22.2)$ & $29(31.2)$ & $21(37.5)$ & $16(48.5)$ \\
Stage III & $5(13.9)$ & $17(18.3)$ & $4(7.1)$ & $4(12.1)$ \\
Stage IV & $1(2.8)$ & $1(1.1)$ & $1(1.8)$ & $1(1.8)$ \\
All stages & $36(100)$ & $93(100)$ & $56(100)$ & $33(100)$ \\
\hline
\end{tabular}

as much as might had been expected [19-22]. The additional benefit of surveillance strategies with shorter interval remains less clear, since the study by Engel et al. showed no difference of CRC incidence between 1-, 2or 3-yearly strategies [23]. We have previously shown that the recommended interval of 3 years lead to lower point estimate of cumulative incidence of CRC compared to recommended 1-2 year intervals [22], which was in conflict with the expected outcome of shorter than 3 years interval [10]. The purpose of the current analysis was to study if shorter time between colonoscopies would result in less advanced cancer stage when CRC was diagnosed. Although this was not a direct comparison of different surveillance strategies, reduced stage was not found to be the additional benefit of more frequent colonoscopies compared to less frequent. In sum, our prospective observational data confirm neither lower incidence nor lower stage of CRCs at diagnosis when shorter intervals between colonoscopies are recommended.

It has been argued that the effectiveness of a 3-yearly interval in Finland is influenced by a less severe phenotype associated with the founder path_MLH1 variant. We analyzed the non-Finnish data separately and found a similar lack of association, indicating that our findings were not explained by the Finnish series having different pathogenic variants to the others. We acknowledge that the aim of the present study was not to study the effects of different classes of path_MMR variants which would need different methods and which we aim to do later.

We have chosen to use a statistically simple method comparing the different intervals between colonoscopies applied in different centres, as well as longer intervals. This way of categorizing data and results is of interest when calculating cost-efficiency of the different strategies for healthcare.

We lack the stage and/or interval information on about $70 \%$ of the total patients registered in the PLSD at the moment. However, we do have complete information from the centres contributing to this study (Table 1). All centres having contributed to the previous PLSD reports were offered the possibility to contribute.

We do not have detailed information on caecal intubation rate, success of bowel preparation or previous adenoma detection rate that are acknowledged key performance indicators associated with colonoscopy quality in sporadic CRC prevention [24]. Although there is limited evidence that they may be associated with the risk of CRC in LS [25], we have no reason to assume that our observation that stage distribution is similar across the different surveillance intervals, is biased by the lack of these data.

The results herein support the hypothesis that in LS, more frequent colonoscopies detect cancers that might not have progressed to clinical recognition and clinical significance. Over-diagnosis is well-recognized 
in screening science especially in relation to prostate and breast cancers [26-29]. Whether these over-diagnosed cancers would have been controlled or even destroyed, through immune and/or other mechanisms or dwell indolently without causing significant morbidity or mortality, has nor been fully clarified.

The relatively good prognosis of CRCs noted in our previous reports from PLSD may reflect that the most but not all cancers produced by the adenoma-carcinoma mechanism are prevented, and the majority of the incident CRCs that we see have a better prognosis because they arise through different carcinogenetic mechanisms. If so, colonoscopy to prevent CRC may have had the expected effect, while (some of) the CRCs that are detected represent different biological tumor phenotypes.

In parallel with the epidemiological studies mentioned above, it is now agreed that path_MMR carriers have multiple MMR deficient/MSI cells in macroscopically normal looking crypts in the colorectal epithelium, and that CRC may develop directly from these without a macroscopically visible adenoma precursor [30,31]. There is a developing understanding that MSI cells present neoantigens on their surfaces that are detectable by the host immune system, making them targets for destruction by the host [32]. Whether or not one of the MMR deficient crypts develops into a CRC may be dependent upon the mutator phenotype rendering a progenitor cell capable of evading the host immune system [33].

The current paper does not aim to discuss these immunological and commonly agreed mechanisms in detail. They are presented and discussed elsewhere, but the topic is offered as supporting evidence that MSI cells may be killed by the host immune system. The probability that a path_MMR carrier develops CRC may be considered a balance between the probability of developing precancerous cells and the probability that the immune system will kill them before they become invasive cancers.

Our offered hypothesis is based on spontaneous regression of cancers. The case report by Karakuchi et al. of spontaneous regression of an MSI high cancer in the transverse colon, assumed to be caused by non-germline acquired somatic $M M R$ mutations but not tested to exclude germline pathogenic variants, is supportive [34]. This does not exclude other mechanisms, as mentioned above.

Clearly, carcinogenesis is a multifactorial process and other biological explanations may be offered. If our interpretation of the findings we describe above contains some truth, it does not imply that other hypotheses - including the accelerated adenoma-carcinoma sequence, the possibly important role of missed lesions during suboptimal surveillance colonoscopy, and cancers developing without a detectable and therefore intervention-susceptible precursor lesion - are not true. We cannot completely exclude an important influence of variable quality of endoscopy or some other geographical variable in response to surveillance but the simplest and most persuasive explanation is that having progressed quickly, often from an unrecognizable precursor, a proportion of these cancers regress spontaneously and those that survive tend to remain as a localized lesion, unlikely to metastasize early.

\section{Conclusions}

The PLSD was designed to examine whether or not the expectations derived from current paradigms alone are met, with the basic understanding that if current paradigms may not completely explain what we find, there may be additional instrumental factors to consider. The combined epidemiological results from the PLSD now raise the possibility that some LS-associated CRCs may spontaneously regress. We can find no published epidemiological evidence on the effects of surveillance colonoscopy, which are in conflict with our hypothesis. The concept of over-diagnosis is well established in other fields of cancer screening. The growing body of knowledge on how the host immune system fights abnormal cells in path_MMR carriers may be interpreted as support for our hypothesis. We suggest that the hypothesis presented here should be further tested because of its scientific interest and especially because the consequences would be of interest to the path_MMR carriers and to the providers of health care. A controlled study comparing the longest safe colonoscopy interval to the shortest possible interval should be able to elucidate the existence of possible over-diagnosis caused by intense monitoring.

\section{Abbreviations}

AJCC: American Joint Committee on Cancer; CRC: Colorectal cancer; HNPCC: Hereditary nonpolyposis colorectal cancer; LS: Lynch Syndrome; MMR: Mismatch repair; path_MLH1: Pathogenic (disease-causing) variant of the MLH1 gene; path_MSH2: Pathogenic (disease-causing) variant of the MSH2 gene; path_MSH6: Pathogenic (disease-causing) variant of the MSH6 gene; path_PMS2: Pathogenic (disease-causing) variant of the PMS2 gene

\section{Acknowledgements}

We would like to express our gratitude to Heikki Järvinen, Beatrix Alcala-Repo and Marianne Haeusler for their efforts during the years.

\section{Funding}

TTS is supported by the Emil Aaltonen Foundation, the Finnish Medical Foundation, the Instrumentarium Science Foundation and Sigrid Juselius Foundation.

DGE and EJC are both supported through the National Institute for Health Research Manchester Biomedical Research Centre (IS-BRC-1215-20007). The Finnish contribution: The Finnish Cancer Foundation, Jane and Aatos Erkko foundation and State Research Funding.

The Spanish contribution: Spanish Ministry of Economy and Competitiveness, the Carlos III Health Institute, the Scientific Foundation Asociación Española

Contra el Cáncer and the Government of Catalonia.

The Welsh Contribution: Wales Gene Park.

The Norwegian contribution: Norwegian Cancer Society, contract 194751-2017 for funding.

The study sponsors did not have a role in planning the study design; in the collection, analysis, or interpretation of data; in the writing of the report; or in the decision to submit the paper for publication. 


\section{Availability of data and materials}

The datasets used and/or analysed during the current study are available from the corresponding author on reasonable request. We have published a website www.lscarisk.org on which cancer risks for all published data can be reviewed and calculated in graphic form.

\section{Authors' contributions}

TTS and PM designed the study, drafted the manuscript, collected the feedback and revised the manuscript accordingly. TTS conducted the statistical analysis. PM and MD-V managed the PLSD data. All authors participated in PLSD data collection. All authors read, critically commented, and approved the final manuscript.

\section{Ethics approval and consent to participate}

All reporting centers obtained informed consent for genetic testing and surveillance procedures. De-identified data was exported for the current study. No named registry needing approval was established for the current study.

\section{Consent for publication}

\section{Not applicable.}

\section{Competing interests}

Toni Seppälä: a co-owner (20\%) of Healthfund Finland Oy (educational and health care services in Finland, not related to patients or scope of this manuscript). Travel costs to a scientific meeting by Medtronic Finland. John Burn: a patent for high speed low cost tumor profiling pending to John Burn and QuantuMDx.

All others: None declared.

\section{Publisher's Note}

Springer Nature remains neutral with regard to jurisdictional claims in published maps and institutional affiliations.

\section{Author details}

'Department of Surgery, Helsinki University Central Hospital, P.O. Box 340, 00029 HUS Helsinki, Finland. ${ }^{2}$ University of Helsinki, Helsinki, Finland. ${ }^{3}$ Heidelberg University Hospital and DKFZ, Heidelberg, Germany. ${ }^{4}$ Department of Tumor Biology, Institute of Cancer Research, The Norwegian Radium Hospital, part of Oslo University Hospital, Olso, Norway. ${ }^{5}$ Department of Medical Genetics, The Norwegian Radium Hospital, Oslo University Hospital, Oslo, Norway. ${ }^{6}$ The Royal Melbourne Hospital, Melbourne, Australia. ${ }^{7}$ University of Melbourne, Melbourne, Australia. ${ }^{8}$ University of Manchester \& Manchester University Hospitals Foundation Trust, Manchester, UK. ${ }^{9}$ The Danish HNPCC Register, Clinical Research Centre, Copenhagen University Hospital, Hvidovre, Denmark. ${ }^{10}$ Medical Genetics, Cardiff University, Cardiff, UK. ${ }^{11}$ University of Newcastle and the Hunter Medical Research Institute, Callaghan, Australia. ${ }^{12}$ University of Newcastle, Newcastle upon Tyne, UK. ${ }^{13}$ University Witten-Herdecke, Wuppertal, Germany. ${ }^{14}$ Dept. of Surgical Gastroenterology, Aalborg University Hospital, Aalborg, Denmark.

${ }^{15}$ Medizinische Klinik und Poliklinik IV, Campus Innenstadt, Klinikum der Universität München, Munich, Germany. ${ }^{16}$ MGZ- Medical Genetics Center, Munich, Germany. ${ }^{17}$ Central Finland Central Hospital, Education and Research, Jyväskylä, Finland. ${ }^{18}$ Department of Clinical Genetics, Aalborg University Hospital, Aalborg, Denmark. ${ }^{19}$ Karolinska Institutet, Stockholm, Sweden. ${ }^{20}$ Hadassah Medical Center, Jerusalem, and Sheba Medical Center, Tel-Hashomer, Ramat-Gan, Israel. ${ }^{21}$ Institute of Human Genetics, University of Bonn, Bonn, Germany. ${ }^{22}$ Department of Internal Medicine I, University Hospital Bonn, Bonn, Germany. ${ }^{23}$ Center for Hereditary Tumor Syndromes, University Hospital Bonn, Bonn, Germany. ${ }^{24}$ Institute for Medical Genetics and Pathology, University Hospital Basel, Basel, Switzerland. ${ }^{25} \mathrm{Hospital}$ Fuerzas Armadas, Grupo Colaborativo Uruguayo, Investigación de Afecciones Oncológicas Hereditarias (GCU), Montevideo, Uruguay. ${ }^{26}$ Tel-Aviv Soursky Medical Center, Tel-Aviv, Israel. ${ }^{27}$ Department of Gastroenterology and Hepatology, Isala Clinics, Zwolle, The Netherlands. ${ }^{28}$ Department of Gastroenterology and Hepatology, Leiden University Medical Centre, Leiden, The Netherlands. ${ }^{29}$ Institute for Medical Informatics, Statistics and Epidemiology, University of Leipzig, Leipzig, Germany. ${ }^{30}$ Medical School, Institute of Human Genetics, Heinrich-Heine-University, Düsseldorf, Germany. ${ }^{31}$ Department of Medicine, Knappschaftskrankenhaus, Ruhr-University Bochum, Bochum, Germany. ${ }^{32}$ St Mark's Hospital, Department of Surgery and Cancer, Imperial College London, London, UK. ${ }^{33}$ University of Manchester and St Mary's Hospital, Manchester, UK. ${ }^{34}$ Hereditary Cancer Program, Catalan Institute of Oncology, Insititut d'Investigació Biomèdica de Bellvitge (IDIBELL), ONCOBELL Program, L'Hospitalet de Llobregat, Barcelona, Spain. ${ }^{35}$ Centro de Investigación Biomédica en Red de Cáncer (CIBERONC), Barcelona, Spain.

${ }^{36}$ University Medical Center Groningen, Groningen, the Netherlands. ${ }^{37}$ Leids Universitair Medisch Centrum, Leiden, Netherlands. ${ }^{38}$ Department of Surgical Gastroenterology, Aarhus University Hospital, Aarhus, Denmark. ${ }^{39}$ Department of Health Sciences Research, Mayo Clinic, Scottsdale, AZ, USA. ${ }^{40}$ Center for Bioinformatics, Department of Informatics, University of Oslo, Oslo, Norway. ${ }^{41}$ Department of Medical Genetics, Aarhus University Hospital, Aarhus, Denmark. ${ }^{42}$ Department of Surgery, Central Finland Central Hospital, Jyväskylä, Finland. ${ }^{43}$ Faculty of Sport and Health Sciences, University of Jyväskylä, Jyväskylä, Finland. ${ }^{44}$ University of Oslo, Oslo, Norway. ${ }^{45}$ Harvard School of Public Health, Boston, MA, USA.

Received: 30 January 2019 Accepted: 20 February 2019

Published online: 28 February 2019

\section{References}

1. Hill MJ, Morson BC, Bussey HJ. Aetiology of adenoma--carcinoma sequence in large bowel. Lancet. 1978;1:245-7.

2. Mecklin JP. Frequency of hereditary colorectal carcinoma. Gastroenterology. 1987;93:1021-5.

3. Jass JR, Stewart SM. Evolution of hereditary non-polyposis colorectal cancer. Gut. 1992;33:783-6.

4. Järvinen HJ, Mecklin JP, Sistonen P. Screening reduces colorectal cancer rate in families with hereditary nonpolyposis colorectal cancer. Gastroenterology. 1995;108:1405-11.

5. Järvinen HJ, Aarnio M, Mustonen $H$, Aktan-Collan K, Aaltonen LA, Peltomäki $\mathrm{P}$, et al. Controlled 15-year trial on screening for colorectal cancer in families with hereditary nonpolyposis colorectal cancer. Gastroenterology. 2000;118:829-34.

6. Weigl K, Jansen L, Chang-Claude J, Knebel P, Hoffmeister M, Brenner H. Family history and the risk of colorectal cancer: the importance of patients' history of colonoscopy. Int J Cancer. 2016;139:2213-20.

7. Morois S, Cottet V, Racine A, Clavel-Chapelon F, Carbonnel F, Bastide N, et al. Colonoscopy reduced distal colorectal cancer risk and excess cancer risk associated with family history. Cancer Causes Control. 2014;25:1329-36.

8. Hennink SD, van der Meulen-de Jong AE, Wolterbeek R, ASLP C, MCJM B, WFS $C$, et al. Randomized comparison of surveillance intervals in familial colorectal Cancer. J Clin Oncol. 2015;33:4188-93.

9. Vasen HF, Nagengast FM, Khan PM. Interval cancers in hereditary nonpolyposis colorectal cancer (lynch syndrome). Lancet. 1995;345:1183-4.

10. Vasen HFA, Abdirahman M, Brohet R, Langers AMJ, Kleibeuker JH, van Kouwen $\mathrm{M}$, et al. One to 2-year surveillance intervals reduce risk of colorectal cancer in families with lynch syndrome. Gastroenterology. 2010; 138:2300-6.

11. Vasen HFA, Blanco I, Aktán-Collán K, Gopie JP, Alonso A, Aretz S, et al. Revised guidelines for the clinical management of lynch syndrome (HNPCC): recommendations by a group of European experts. Gut. 2013;62:812-23.

12. Aaltonen $L A$, Peltomäki $P$, Leach $F S$, Sistonen $P$, Pylkkänen $L$, Mecklin JP, et al. Clues to the pathogenesis of familial colorectal cancer. Science. 1993;260: 812-6.

13. Peltomäki $P$, Aaltonen $L A$, Sistonen $P$, Pylkkänen $L$, Mecklin JP, Järvinen $H$, et al. Genetic mapping of a locus predisposing to human colorectal cancer. Science. 1993:260:810-2.

14. Lindblom A, Tannergård P, Werelius B, Nordenskjöld M. Genetic mapping of a second locus predisposing to hereditary non-polyposis colon cancer. Nat Genet. 1993;5:279-82.

15. Fishel R, Lescoe MK, Rao MR, Copeland NG, Jenkins NA, Garber J, et al. The human mutator gene homolog MSH2 and its association with hereditary nonpolyposis colon cancer. Cell. 1993;75:1027-38.

16. Nicolaides NC, Papadopoulos N, Liu B, Wei YF, Carter KC, Ruben SM, et al. Mutations of two PMS homologues in hereditary nonpolyposis colon cancer. Nature. 1994:371:75-80.

17. Miyaki M, Konishi M, Tanaka K, Kikuchi-Yanoshita R, Muraoka M, Yasuno M, et al. Germline mutation of MSH6 as the cause of hereditary nonpolyposis colorectal cancer. Nat Genet. 1997;17:271-2.

18. Boland CR, Troncale FJ. Familial colonic cancer without antecedent polyposis. Ann Intern Med. 1984;100:700-1. 
19. Møller P, Seppälä T, Bernstein I, Holinski-Feder E, Sala P, Evans DG, et al. Cancer incidence and survival in lynch syndrome patients receiving colonoscopic and gynaecological surveillance: first report from the prospective lynch syndrome database. Gut. 2017:66:464-72.

20. Møller P, Seppälä T, Bernstein I, Holinski-Feder E, Sala P, Evans DG, et al. Incidence of and survival after subsequent cancers in carriers of pathogenic MMR variants with previous cancer: a report from the prospective lynch syndrome database. Gut. 2017;66:1657-64.

21. Møller P, Seppälä TT, Bernstein I, Holinski-Feder E, Sala P, Gareth Evans D, et al. Cancer risk and survival in path_MMR carriers by gene and gender up to 75 years of age: a report from the prospective lynch syndrome database. Gut. 2018;67:1306-16.

22. Seppälä T, Pylvanainen K, Evans DG, Järvinen H, Renkonen-Sinisalo L, Bernstein I, et al. Colorectal cancer incidence in path_MLH1 carriers subjected to different follow-up protocols: a prospective lynch syndrome database report. Hered Cancer Clin Pract. 2017;15:18. https://doi.org/10. 1186/s13053-017-0078-5.

23. Engel C, Vasen HF, Seppälä T, Aretz S, Bigirwamungu-Bargeman M, de Boer SY, et al. No difference in colorectal Cancer incidence or stage at detection by colonoscopy among 3 countries with different lynch syndrome surveillance policies. Gastroenterology. 2018;155:1400-2.

24. Rees CJ, Thomas Gibson S, Rutter MD, Baragwanath P, Pullan R, Feeney M, et al. UK key performance indicators and quality assurance standards for colonoscopy. Gut. 2016;65:1923-9.

25. Haanstra JF, Vasen HFA, Sanduleanu S, van der Wouden EJ, Koornstra JJ, Kleibeuker JH, et al. Quality colonoscopy and risk of interval cancer in lynch syndrome. Int J Color Dis. 2013;28:1643-9.

26. Gøtzsche PC, Jørgensen KJ. Screening for breast cancer with mammography. Cochrane Breast Cancer Group, editor. Cochrane Database Syst Rev. 2013;156:CD001877.

27. Miller AB, Wall C, Baines CJ, Sun P, To T, Narod SA. Twenty five year followup for breast cancer incidence and mortality of the Canadian National Breast Screening Study: randomised screening trial. BMJ. 2014;348:g366.

28. Jørgensen KJ, Gøtzsche PC, Kalager M, Zahl P-H. Breast Cancer screening in Denmark: a cohort study of tumor size and Overdiagnosis. Ann Intern Med Am Coll Physicians. 2017;166:313-23.

29. Ilic D, Neuberger MM, Djulbegovic M, Dahm P. Screening for prostate cancer. Cochrane Urology Group, editor. Cochrane Database Syst Rev. 2013; (107):CD004720.

30. Kloor M, Huth C, Voigt AY, Benner A, Schirmacher P, Knebel-Doeberitz von $M$, et al. Prevalence of mismatch repair-deficient crypt foci in lynch syndrome: a pathological study. Lancet Oncol. 2012;13:598-606.

31. Ahadova A, Gallon R, Gebert J, Ballhausen A, Endris V, Kirchner M, et al. Three molecular pathways model colorectal carcinogenesis in lynch syndrome. Int J Cancer. 2018;143:139-50.

32. Schwitalle $Y$, Kloor M, Eiermann S, Linnebacher M, Kienle P, Knaebel HP, et al. Immune response against frameshift-induced Neopeptides in HNPCC patients and healthy HNPCC mutation carriers. Gastroenterology. 2008;134:988-97.

33. Kloor M, Knebel-Doeberitz von M. The immune biology of microsatelliteunstable Cancer. Trends Cancer. 2016;2:121-33.

34. Karakuchi N, Shimomura M, Toyota K, Hinoi T, Yamamoto H, Sadamoto S, et al. Spontaneous regression of transverse colon cancer with high-frequency microsatellite instability: a case report and literature review. World J Surg Oncol. 2019:17:19.

35. Stormorken AT, Clark N, Grindedal E, Mæhle L, Møller P. Prevention of colorectal cancer by colonoscopic surveillance in families with hereditary colorectal cancer. Scand J Gastroenterol. 2007;42:611-7.

36. Mecklin J-P, Aarnio M, Läärä E, Kairaluoma MV, Pylvänäinen K, Peltomäki $P$, et al. Development of colorectal tumors in colonoscopic surveillance in lynch syndrome. Gastroenterology. 2007;133:1093-8.

37. Pylvänäinen K, Kairaluoma M, Mecklin J-P. Compliance and satisfaction with long-term surveillance in Finnish HNPCC families. Familial Cancer. 2006;5:175-8.

38. Lindgren $G$, Liljegren A, Jaramillo E, Rubio C, Lindblom A. Adenoma prevalence and cancer risk in familial non-polyposis colorectal cancer. Gut. 2002;50:228-34.

39. Forsberg A, Kjellström L, Andreasson A, Jaramillo E, Rubio CA, Björck E, et al. Colonoscopy findings in high-risk individuals compared to an average-risk control population. Scand J Gastroenterol. 2015;50:866-74.
40. Olsen KR, Bojesen SE, Gerdes A-MM, Lindorff-Larsen K, Bernstein IT. Costeffectiveness of surveillance programs for families at high and moderate risk of hereditary non-polyposis colorectal cancer. Int J Technol Assess Health Care. 2007;23:89-95.

41. Newton K, Green K, Lalloo F, Evans DG, Hill J. Colonoscopy screening compliance and outcomes in patients with lynch syndrome. Color Dis. 2015;17:38-46.

\section{Ready to submit your research? Choose BMC and benefit from:}

- fast, convenient online submission

- thorough peer review by experienced researchers in your field

- rapid publication on acceptance

- support for research data, including large and complex data types

- gold Open Access which fosters wider collaboration and increased citations

- maximum visibility for your research: over $100 \mathrm{M}$ website views per year

At BMC, research is always in progress.

Learn more biomedcentral.com/submissions 